\title{
NOVAS/VELHAS FORMAS DE ORGANIZAÇÃO E EXPLORAÇÃO DO TRABALHO: A PRODUÇÃO "INTEGRADA" NA AGROINDÚSTRIA
}

\author{
Vitor Araújo Filgueiras ${ }^{l}$
}

\begin{abstract}
RESUMO
0 presente texto analisa a denominada "produção integrada" na agroindústria brasileira. A "integração" é uma forma de organização da produção e trabalho na qual uma empresa tomadora dos serviços firma contrato de exclusividade com supostos produtores rurais para fornecimento de determinado produto componente de seu processo produtivo. 0 modelo empreendido é um aparente monopsônio, mas na verdade constitui uma relação de assalariamento comum, sob tentativa de disfarce pouco arrojada. Há amplo controle do tomador de serviços sobre o processo produtivo dos "integrados", que têm se tornado intermediadores de mão de obra ou apenas um empregado em meio aos demais envolvidos na produção. Os corolários da "integração" têm sido a extrema subsunção dos trabalhadores à empresa contratante e a brutal precarização de todos os trabalhadores (inclusive crianças) envolvidos. Além de revisão e discussão da literatura sobre esse modelo, este texto apresenta pesquisa efetuada em dois empreendimentos do setor avícola no nordeste da Bahia que adotam o modelo da "integração".
\end{abstract}

Palavras chave: Integração. Assalariamento. Precarização. Subsunção do trabalho.

1 Pós-doutorando do Instituto de Economia da Universidade Estadual de Campinas, Brasil. fvitor@hotmail.com. 


\title{
NEW/OLD WAYS OF ORGANIZING AND EXPLOITING LABOR: THE “INTEGRATED” PRODUCTION IN THE AGRIBUSINESS
}

\begin{abstract}
This paper analyzes the so-called "integrated production" in Brazilian agribusiness. "Integration" is a way of organizing production and labor in which a utility company establishes an exclusivity agreement with alleged rural farmers for the supply of a certain product. The applied model is, apparently, a monopsony, but constitutes, in fact, an ordinary, poorly disguised wage labor relationship. The utility company largely controls the productive process of the "integrated", who have become mediators of the work force or mere employees among the many involved in the production process. The corollaries of integration have signified the extreme subsumption and impoverishment of all workers (including children) by the utility company. In addition to reviewing and discussing the literature on this model, the present text presents a research conducted on two integrationist, avicultural breeding companies in the northeast of Bahia.
\end{abstract}

Keywords: Integration. Wage labor. Impoverishment. Subsumption of labor.

\section{INTRODUÇÃO}

s últimas décadas têm sido palco de uma série de medidas gerenciais orquestradas
pelo capital com dois efeitos complementares, apesar de aparentemente
contraditórios: recrudescem a subsunção do trabalho e escamoteiam essa mesma subsunção para supostamente deixar de contratar trabalhadores na condição de empregados, e de fato, abstrair as normas de proteção ao trabalho. Desse modo, o capital tem conseguido trabalhadores mais disciplinados, dedicados e com menor custo e maior flexibilidade de contratação e gestão.

Eufemismos utilizados pelas empresas brasileiras para a contratação de trabalhadores sem anotar suas carteiras de trabalho são comuns e se intensificaram, especialmente a partir da década de 1990. Houve uma multiplicação dos "cooperados", das "consultoras", dos "PJ", etc. No plano imediato, esses artifícios são interessantes ao capital por diminuir os custos de contratação e uso da força de trabalho (não há pagamento de férias, décimo terceiro salário, descanso semanal, fundo de garantia, etc.), ao mesmo tempo em que torna mais flexível a relação (a despedida ocorre a qualquer tempo e sem custos). Contudo, tão ou mais importante do que o ganho financeiro imediato, é que a sonegação dos direitos implica uma maior subsunção do trabalho ao

\footnotetext{
${ }^{2}$ Como são conhecidos os trabalhadores obrigados a realizar inscrição na Receita Federal como pessoas jurídicas.
} 
capital. Ressalte-se que, em muitos casos, o incremento da subsunção não é um efeito colateral da subtração dos direitos, mas o inverso: o não reconhecimento do vínculo de emprego é um instrumento deliberadamente adotado pelo capital para, ao precarizar 0 trabalho, incrementar sua subordinação e produtividade. Este texto se apoia em pesquisa empírica de dois casos paradigmáticos da relação de causalidade instrumental entre precarização e subsunção.

Ao impor condições precárias de contratação e remuneração ao trabalhador por meio de uma pseudo-autonomia (mas, de fato, responsabilização pelos riscos do negócio), o capital engendra forte pressão sobre ele para atenuar essa mesma precarização. Assim, desesperado para manter o vínculo que lhe permite se reproduzir, inclusive fisicamente, e concomitantemente premido pela necessidade de elevar seus rendimentos, o trabalhador tende a se dedicar ao máximo aos objetivos do capital, com reduzida propensão ao questionamento individual ou coletivo ${ }^{3}$.

Empreitadas do capital para driblar o direito do trabalho não são novidades Marx (2002), por exemplo, apresenta diversos exemplos empíricos ainda no século XIX -, porém, é no atual contexto de hegemonia do capital financeiro e perseguição da acumulação flexível que a adoção de disfarces do assalariamento é mais funcional e, por isso, se generalizou.

A chamada produção "integrada" se insere nesse cenário como mais uma forma de precarização e intensificação da exploração do trabalho. A "integração" é uma estratégia adotada por empresas de diferentes setores agroindustriais brasileiros para a organização de parte (ou todo) do seu processo produtivo. Elas contratam com exclusividade supostos e/ou pequenos produtores rurais para fornecimento de produtos. Esses produtos são constituintes do processo produtivo das empresas, quando não são as próprias mercadorias finais vendidas por essas tomadoras de serviços, que financiam, são proprietárias dos insumos, detêm o know how e determinam a técnica adotada no processo produtivo, incumbindo ao "integrado", de fato, agregar valor à mercadoria através do dispêndio do seu trabalho.

0 objetivo deste texto é discutir a natureza da organização da produção e do trabalho no Brasil através do chamado sistema "integrado". A pesquisa na qual se baseou o presente artigo teve início em duas fazendas que adotam o sistema "integrado" como forma de organização do trabalho na região nordeste da Bahia. Foram efetuadas inspeções nos estabelecimentos, entrevistados trabalhadores, ouvidos os prepostos das empresas e analisados diversos documentos. Também foram utilizadas informações dos sistemas informatizados: CAGED (Cadastro Geral de Empregados e Desempregados),

\footnotetext{
${ }^{3}$ Segundo Bourdieu (1998, p. 123), a empresa flexível explora uma situação de insegurança que ela deliberadamente contribui para reforçar.
} 
RAIS (Relação Anual de Informações Sociais) e FGTS (Fundo de Garantia por tempo de Serviço). A estes estudos de caso foram agregados outros trabalhos existentes na literatura sobre o modelo de "integração" em outros segmentos rurais de diferentes regiões do país.

\section{A “INTEGRAÇÃO” COMO FORMA DE ORGANIZAÇÃO DA PRODUÇÃO E TRABALHO}

A "integração" como forma de organização do trabalho não é uma novidade no campo brasileiro, havendo registros de sua adoção por empresa ainda no primeiro quarto do século XX. Entretanto, essa estratégia de organização ganhou força nas últimas décadas, se espalhando por diversos setores da agroindústria, dada a sua pertinência às demandas contemporâneas do capital.

0 sistema de "integração" teve origem no sul do país, na cultura do fumo. De acordo com Pincelli (2005), essa forma de organização da produção foi desenvolvida pela empresa Souza Cruz de modo intencional e planejado, e não pode ser concebida como uma tradição da agricultura familiar da região ${ }^{4}$.

Atualmente identificamos três variantes da "integração", quais sejam: a "integração" através de proprietário rural de relevante porte econômico, a "integração" através de pequeno proprietário de terra ${ }^{5}$ e o sistema no qual o "integrado" é alocado no interior da própria empresa tomadora dos serviços.

Em síntese, a proposta original da chamada "integração" consiste na contratação, por empresa produtora de determinado bem, de pequenos produtores rurais para realização de etapa do seu processo produtivo. 0 "integrado" seria um pequeno proprietário de terra, que faria um contrato de exclusividade para fornecer o bem demandado pela tomadora dos serviços. A empresa contratante fornece a matéria prima a ser trabalhada (os pintos, os filhotes dos porcos, no caso da fumicultura, o chamado "pacote tecnológico", etc.), os insumos, determina os padrões técnicos da atividade, dentre outros, cabendo ao "integrado" atender com exclusividade à demanda da tomadora dos serviços. 0 "integrado" devolve a produção (o fumo, os ovos, as aves para

\footnotetext{
4 " 0 sistema de integração foi construído e introduzido pela Souza Cruz (...). A fumicultura integrada foi planejada pela empresa com base nos conhecimentos adquiridos a respeito das condições climáticas e da tradição de produção familiar em pequenas propriedades na região sul do Brasil" (PINCELLI, 2005, p. 77). Ou seja, a empresa se utilizou de uma tradição de produção familiar para formatar o sistema "integrado", mas não fazia parte da tradição da produção familiar tal modo de organização.

${ }^{5}$ Segundo Pelegrini e Cleps Junior (2001, p. 1), "a produção familiar tem sido, tradicionalmente, responsável pelo desenvolvimento de diversas atividades rurais, a exemplo da avicultura, fumicultura, vitivinicultura e suinocultura, em pequenas propriedades, sob regime de integração com as agroindústrias".
} 
corte, os porcos para abate, etc.) no ponto desejado pela empresa, que the remunera por isso.

De início (desde a idealização do modelo) fica evidente que o empreendimento no qual se insere a "integração" é o empreendimento da empresa tomadora de serviços, pois, mesmo que a terra seja formalmente propriedade do "integrado", a demanda e 0 processo produtivo são do tomador. 0 "integrado" figura, se muito, como peça da atividade empresarial da tomadora de serviço. Do ponto de vista organizativo e formal (por contrato) estaríamos diante de um monopsônio, o que, per si, já ajuda a revelar a natureza da relação engendrada. 0 monopsônio é uma estrutura de mercado na qual a demanda se constitui por apenas um comprador e a oferta é composta por vários vendedores. É inerente ao monopsônio o total desequilíbrio entre as partes negociantes, pois aos vendedores nenhuma opção resta que não vender os produtos ao único comprador, nas condições que este impuser. Trata-se de um monopólio às avessas. Todo o poder é apreendido pelo comprador único, e não por acaso os monopólios são necessariamente e fortemente regulados, quando não combatidos juridicamente em todas as economias de mercado.

Contudo, a "integração" não é meramente um monopsônio, pois há ingerência do suposto comprador único em todo o processo produtivo dos supostos vendedores. A produção dos bens é aspecto constituinte do empreendimento do tomador de serviços. Não bastasse, o produto, em si, já é propriedade da empresa contratante, recebendo o "integrado" apenas a diferença relativa ao trabalho agregado.

$\mathrm{Na}$ produção "integrada" de pequenos produtores donos da terra, poderia se pensar que a propriedade de meio relevante de produção (a terra) e a não estrita parcelização do trabalho reduziriam a subsunção dos trabalhadores às empresas tomadoras (estaríamos diante de um caso mais próximo da subsunção formal do que real, em termos marxianos). Todavia, os mecanismos empregados pelas empresas tendem a eliminar essa pretensa autonomia e tornar o "integrado" apêndice do (comandado pelo) processo de valorização.

Vejamos, inicialmente, a partir de um texto de SCARE, SILVA, TAVARES, $2010^{6}$, que faz apologia expressa à denominada produção "integrada", como é possível extrair implícita ou mesmo explicitamente a natureza da relação estabelecida entre tomador de serviços e trabalhadores. 0 trabalho analisa a ampliação das atividades empresariais de um frigorífico (denominado Frango de Ouro) na região oeste da Bahia, que substituiu a aquisição de frangos de produtores independentes pela "produção integrada". Portanto, estamos diante de uma ação empreendida pela Frango de Ouro:

\footnotetext{
${ }^{6}$ Segundo os autores, o texto foi desenvolvido “(...) com o objetivo de planejar e implementar o pólo avícola de Barreiras".
} 
(...) conforme as compras cresceram, os sócios da empresa notaram que 0 modelo de produção integrada poderia reduzir os riscos de variações na oferta de frangos e também diminuiria o custo por ave entregue ao frigorífico, devido à economia de escala (SCARE, SILVA, TAVARES, 2010, p. 38).

Trata-se, portanto, de um empreendimento do tomador de serviços (Frango de Ouro). Esta empresa deveria selecionar os "integrados", entregar os pintos aos "integrados", fornecer os insumos, inclusive produzindo a ração, remunerar 0 "integrado" por ave, fornecer produtos veterinários, assistência técnica e de gestão. Aos "integrados" caberia criar as aves atendendo ao padrão de qualidade determinado pela Frango de Ouro, adotando as técnicas de manejo e insumos fornecidos pela empresa. Com relação aos fatores de sucesso da "integração", o artigo diz textualmente que, dentre estes fatores, está "a seleção criteriosa dos produtores, seguida da sua capacitação, treinamento e acompanhamento por parte da Frango de Ouro (...)" (p. 41):

Para isso foi elaborado um modelo de seleção que contempla análise de itens eliminatórios e outros de pontuação do produtor e de sua propriedade, conforme as exigências técnicas da atividade e os atributos que a frango de ouro julga importante. Ao final, os candidatos que atenderem aos itens eliminatórios e obtiverem melhor pontuação serão admitidos no processo de integração (SCARE, SILVA, TAVARES, 2010, p. 41) (grifos nossos).

Dentre os itens considerados para admissão do "integrado", o texto cita: escolaridade, antecedentes criminais, tempo disponível, mão de obra familiar. Durante o contrato, segundo o texto, o "integrado" receberá acompanhamento permanente pela Frango de Ouro. 0 texto é detalhado, revelando fartamente a natureza do próprio conceito de "integração" como forma de contratação e gestão do trabalho. A empresa tomadora controla até os antecedentes criminais dos admitidos. 0 controle técnico da produção desidrata a pretensa autonomia que teria o "integrado".

Também no setor avícola baiano, em Conceição de Feira e São Gonçalo dos Campos, foi efetuada pesquisa (CONCEIÇÃO, 2007) sobre a produção "integrada" através de pequenos produtores, proprietários das terras. 0 autor revela que um dos itens fundamentais para a seleção dos "integrados" pelas empresas tomadoras é a existência de mão de obra familiar para ser empregada na criação das aves. Para as empresas contratantes, o "integrado" e sua família, pressionados pelo fato de a remuneração ser totalmente variável de acordo com a produção tendem a se dedicar com maior afinco ao labor, diferentemente de trabalhadores de fora da propriedade que o próprio "integrado" hipoteticamente trouxesse para auxiliá-lo. Além disso, a contratação de trabalhadores 
que não pertencem ao núcleo familiar exerceria pressão na remuneração do "integrado", já que este teria que arcar com os custos do trabalhador admitido, dificultando o sucesso da produção "integrada".

A pesquisa corrobora o controle do processo produtivo pelas empresas tomadoras dos serviços, que definem até o que os "integrados" podem produzir em suas propriedades: "para que consiga atingir melhores índices de eficiência produtiva, o produtor é levado a atender as orientações técnicas da empresa que chegam, por exemplo, a proibir a criação de outras aves (a exemplo do frango caipira) no interior das propriedades integradas" (CONCEIÇÃO, 2007, p. 246). A empresa contratante impõe (inclusive contratualmente) as regras da produção fora e dentro da propriedade do integrado, "determinando por exemplo, o tipo de criação (raça, sexo e finalidade das aves), quando será feito o alojamento e a retirada das aves e os objetos técnicos utilizados na criação" (CONCEIÇÃO, 2007, p. 253). A empresa contratante também tem poder para "acompanhar" e "fiscalizar" o processo produtivo no interior de sua [do "integrado"] propriedade.

Por fim, o financiamento dos instrumentos necessários à produção é feito pela própria empresa contratante: "O pagamento das parcelas do financiamento se dá diretamente pela empresa a partir dos descontos efetivados no rendimento do integrado no fechamento de cada lote" (CONCEIÇÃO, 2007, p. 250). Desse modo, o "integrado" fica preso à relação e mais sujeito aos ditames da empresa. Essa estratégia do financiamento não é particularidade da avicultura, e a submissão engendrada por ela pode chegar às últimas consequências. A conclusão do autor é de que "as empresas conduzem o processo produtivo determinando o quê, como, quando e quanto vai ser produzido, onde será produzido e, por fim, quanto será pago ao produtor integrado" (CONCEIÇÃO, 2007). Assim, a propriedade rural do "integrado" como meio de produção termina sendo mais formal do que efetiva.

Ainda na "integração" que utiliza pequenos produtores proprietários de terra, temos o caso da fumicultura no sul do país. Este parece ser o mais antigo modelo de "integração" existente no Brasil, mas nos últimos anos os mecanismos de controle da produção e do trabalho dos produtores "integrados" pelo capital têm se refinado e intensificado.

Os principais instrumentos de controle dos trabalhadores pelas empresas são 0 domínio da tecnologia empregada para cultivo e o financiamento da produção, que tendem a tornar os pequenos produtores reféns da empresa contratante. As péssimas condições de trabalho dos "integrados", a incidência de trabalho infantil - que atingiria 80 mil crianças no estado do Paraná (MINISTÉRIO PÚBLICO DO TRABALHO, 2007) - e o adoecimento dos trabalhadores provocado pela utilização dos agrotóxicos determinados pelas empresas redundaram no ajuizamento de uma Ação Civil Pública 
pelo Ministério Público do Trabalho no Paraná contra as empresas de tabaco. A petição inicial do Ministério Público do Trabalho (2007, p. 6-7) indica como se engendra o processo de dominação dos "integrados" pelas empresas:

Os pequenos produtores rurais, após convencidos da "vantagem" de se tornarem produtores de fumo, assumem dívidas perante instituições financeiras que os manterão atrelados à atividade por anos seguidos, querendo ou não permanecer produzindo fumo, sob pena, inclusive, de perda de seu único patrimônio, que é a sua pequena propriedade agrícola, único meio de subsistência. Tal endividamento caracteriza, sem sombra de dúvidas, submissão dos trabalhadores rurais aos interesses econômicos das empresas.

0 corolário desse processo de subordinação é a perda do controle efetivo da terra pelos "integrados", que se vêem entregues aos ditames das empresas contratantes sob pena de perder sua propriedade. E isso de fato acontece, com a expropriação da terra dos inadimplentes pela empresa contratante, conforme exemplifica a ação civil. 0 comando da empresa não se atém ao resultado global da produção, mas atinge o próprio processo de trabalho dos "integrados":

(...) para produzir o fumo eles teriam, obrigatoriamente, de empregar sua força de trabalho, assim como de ajudantes e de pessoas de sua família, em turnos praticamente ininterruptos, inclusive não raramente tendo que "dormir" dentro da estufa de fumo, local dos mais insalubres, dada a quantidade de agrotóxicos aplicados nas plantas e que são, assim, diuturnamente inspirados por quem lá esteja (MINISTÉRIO PÚBLICO DO TRABALHO, 2007, p. 7).

Desse modo, o que de fato tende a ocorrer na "integração" na fumicultura, como nos exemplos anteriormente apresentados, é a perda do controle do processo produtivo pelo proprietário formal da terra. Mais do que perder a autonomia da produção, sendo dragado por um esquema que lhe torna atendente cativo das demandas da empresa, o próprio processo de trabalho se torna aspecto do processo de valorização do capital, levando os trabalhadores a estranhamentos profundos como dormir na estufa do fumo, se envenenar com os agrotóxicos fornecidos pelas empresas ou simplesmente trabalhar ininterruptamente sem folga. A produção do fumo passa a ser a produção da empresa fabricante de tabaco, virando o "integrado" mero apêndice no processo.

Uma variante do sistema "integrado" é a utilização de produtores "integrados" de maior porte pelas empresas contratantes. Segundo Pelegrini e Cleps Junior (2001, p. 1), muitos autores veem a "integração" por meio de grandes produtores como um 
caminho inexorável para o sistema na suinocultura, que eliminaria a "integração" da produção familiar, pois ele viabilizaria:

(...) a melhoria da eficiência produtiva, em consequiência do esgotamento do sistema tradicional de integração, baseado na pequena produção familiar. A ênfase deste argumento consiste em que os novos padrões tecnológicos e o crescimento da escala de produção tornam possível a conjugação de interesses de produtores e indústria, cuja solidariedade produtiva permite incrementos de competitividade num mercado cada vez mais mundializado.

0 "integrado", nesse caso, não é um trabalhador. Por outro lado, o texto demonstra claramente que o empreendimento continua sendo da empresa tomadora, que procura os "integrados" mais aptos à consecução dos interesses da primeira. Tanto assim que a contratante evita "integrar" proprietários demasiadamente grandes para não reduzir seu poder de imposição de condições nos negócios. Os trabalhadores laboram para o tomador de serviços através do "integrado", que é um intermediário que se beneficia do esquema absorvendo um delta da riqueza social produzida.

Portanto, a ideia original da "integração" era a produção do bem demandado pela empresa contratante através de pequenos produtores proprietários de terra, que laboravam diretamente na atividade com as famílias e/ou ajudantes. Por peculiaridades estratégicas de empresas tomadoras, foi introduzida uma variante no sistema de "integração", realizado agora também através de maiores proprietários de terra, que não trabalham diretamente na atividade. Assim, a "integração" pode ocorrer através de pequenos proprietários ou grandes fazendeiros. Contudo, ela é adotada também através do emprego de não proprietários, conforme veremos na seção seguinte deste texto.

Em todos os casos, o chamado "integrado" se enquadra como intermediário do tomador dos serviços (se beneficiando da precarização dos demais trabalhadores) ou assalariado da empresa tomadora dos serviços. Há subsunção de todos os trabalhadores envolvidos relativamente à contratante, que controla todo o empreendimento. Em qualquer um dos casos de "integração", o contrato civil, se estabelecido entre empresa e "integrado", serve como mecanismo para intermediação de mão de obra pela empresa tomadora dos serviços e instrumento de reforço do controle sobre o "integrado".

Do ponto vista teórico, a "integração" nos moldes originais atinge a problemática das formas de subsunção do trabalho ao capital. Uma visão inicial da "integração" poderia enquadrá-la como um caso de subsunção ainda formal, em termos marxianos, do trabalho ao capital, por conta da propriedade da terra pelo trabalhador e da não parcelização estrita do trabalho, que lhe reservariam alguma 
margem de autonomia sobre a produção e o processo de trabalho ${ }^{7}$. Porém, se no início da "integração", no sul do país, os "integrados" tinham alguma autonomia no processo de trabalho, parece que não há mais vestígio dela. Talvez um "integrado" de grande porte tenha algum poder de barganha para negociar com a empresa contratante o modo de organização e execução do trabalho, todavia, nesse caso não se trata de um assalariado, mas de empresário que se beneficia de trabalhadores em associação com a empresa tomadora do serviço.

Ocorre que, do nosso ponto de vista, a subsunção do trabalho ao capital deve ser apreendida como fenômeno historicamente construído a partir de determinados mecanismos, que muitas vezes são planejados, inclusive. Isso que dizer que os fatores de subsunção do trabalho são instrumentos do capital, e que podem ser alterados a depender das disputas entre as classes ou de particularidades de cada conjuntura da acumulação.

Na gênese e expansão do capital, segundo Marx (2002), a parcelização do trabalho pela produção capitalista e a introdução da maquinaria foram dois instrumentos essenciais para o domínio do capital sobre o trabalho. 0 cerne da questão, para 0 autor, era a insubordinação do trabalho advinda do know bow do trabalhador antes da divisão técnica e automatização do processo produtivo. Acontece que esses dois expedientes foram instrumentos (de sucesso) de subsunção do trabalho num dado contexto, o que não quer dizer que o capital não possa empregar outros métodos em diferentes cenários com o mesmo objetivo. Pensamos que, do ponto de vista do capital, a questão é subsumir o trabalho, não importa como, desde que seja eficiente aos seus propósitos. Desse modo, o fato de haver propriedade formal da terra pelo "integrado", per si, não quer dizer que ele é mais (real) ou menos (formal) subsumido ao capital. Em algumas atividades econômicas (como idealmente pode ser na "integração") no atual contexto de acumulação flexível, até sem a interferência direta do capital este

\footnotetext{
${ }^{7}$ Numa perspectiva ainda mais literal da ótica marxiana da evolução do capitalismo, a "integração" estaria inserida num cenário anterior à fase da cooperação no processo de trabalho (ver Marx, 2002, capítulo XI, livro I), pois apesar de se tratar de somatório de vários produtores individuais em benefício do capital, os trabalhadores sequer são agregados num mesmo processo de trabalho, já que cada um trabalha em sua terra. No limite, estaríamos tratando de uma organização pré capitalista, pois, enquanto a divisão do trabalho pré capitalista engendrava a venda de mercadorias pelos produtores diretos (pelo fato de os meios de produção estarem divididos entre os produtores independentes, o trabalhador vende no mercado cada produto constituinte de um artigo final, como nas diversas etapas entre a criação do gado e a produção do sapato), a divisão técnica do trabalho pressupõe a segmentação dentro do processo de produção de uma mesma mercadoria (cada trabalhador faz uma parte do sapato sob os ditames do capitalista). Acontece que essa venda de mercadoria por produtor supostamente independente pode ser meramente aparente (quando de fato os trabalhadores são assalariados, como no caso dos "integrados"), e organizada de propósito justamente como estratégia de subsunção do trabalho ao capital no atual contexto de busca pela acumulação flexível (disfarçando o assalariamento e precarizando o trabalho).
} 
consegue controlar o processo de trabalho e seu resultado, mediante diferentes instrumentos.

Vale ressaltar, por exemplo, que o Toyotismo diminui, em alguns casos, a parcelização do trabalho, mas nem por isso atenua a subsunção real do trabalho, pelo contrário, é uma nova estratégia de envolvimento cooptado (ANTUNES, 2008) justamente para renovar e aprofundar a subsunção.

0 cerne do debate, segundo pensamos, reside no fato de que quem domina 0 trabalho é o capital (relação social personificada pelo capitalista), e não a máquina, por exemplo. A máquina é um instrumento utilizado pelo capital para subsumir o trabalho. No máximo, podemos afirmar que a máquina, enquanto capital, subsume o trabalho. Mais do que isso engendra o fetiche da máquina, que passa a ter vontade própria como exploradora ${ }^{8}$. Aferir a subsunção do trabalho por quesitos fixos (ontológicos), como a maquinaria, termina por transformar o instrumento em agente vivo (e a-histórico) do fenômeno. 0 que de fato interessa é se o capital consegue ou não impor ao trabalho sua lógica, transformar o processo de trabalho em processo de valorização?

Os fatos já narrados sobre a organização do trabalho através da "integração" indicam que o capital controla amplamente 0 processo de trabalho, determinando 0 que, como, quando, quanto e o preço da produção. Os mecanismos utilizados são especialmente o financiamento e o know how da atividade. Desse modo, torna 0 trabalhador refém e aliena seu trabalho (o trabalhador não tem o controle total, nem mesmo formalmente, da produção da mercadoria, já que segue as instruções da empresa). 0 fato de serem empregadas crianças, os suicídios no fumo, as jornadas ininterruptas e acampamentos nos armazéns do fumo, em nossa opinião, constituem indícios de que há subsunção real no modelo de sistema de "integração" vigente, enquanto perda de controle da atividade e incorporação do trabalho como apêndice à reprodução do capital.

\section{A PRECARIZAÇÃO COMO ESTRATÉGIA DE DOMINAÇÃO}

Os estudos de caso efetuados pela pesquisa que deu origem ao presente texto detectaram não apenas que a "integração" tem engendrado a precarização intensa do trabalho como consequiência dessa modalidade de organização, mas que a precarização do trabalho é instrumental e deliberadamente adotada pelo capital, através da

\footnotetext{
${ }^{8} 0$ capital é quem projeta, dá o ritmo da máquina (acelera, retarda), projeta parcelização do trabalho.

${ }^{9}$ Isso não diminui a importância da parcelização e da maquinaria como dispositivo de passagem da subsunção formal, inicialmente obtida pelo capital, à subsunção real, quando o processo de trabalho é transformado em apêndice do processo de valorização. Apenas queremos ressaltar que são instrumentos de subsunção, e historicamente o capital pode empregar outros.
} 
"integração", como estratégia de aprofundamento da subsunção e exploração do trabalho.

Foram pesquisadas duas fazendas localizadas na cidade de Entre Rios, Bahia. Uma realizava produção de ovos (OT) e outra criação de frangos para corte (CA). Houve inspeções nos estabelecimentos e entrevistas com dezenas de trabalhadores. Também foram ouvidos os prepostos das empresas. Diversos documentos foram analisados, como os contratos de "integração", as instruções de trabalho elaboradas pelas empresas, as atas de reunião entre proprietários das fazendas e trabalhadores "integrados", cartas de dispensa e controle da remuneração dos "integrados". Consta, a seguir, um pequeno resumo dos resultados da investigação:

Até 0 início dos anos 2000 os trabalhadores que criavam as aves nas duas fazendas eram formalmente registrados como empregados por OT e CA. A partir de contatos firmados entre os empregadores e a associação avícola estadual, os primeiros resolveram adotar um novo esquema de contratação dos trabalhadores. Os mesmos funcionários antes registrados como empregados passaram a ser "integrados" das fazendas.

A "integração" foi um procedimento explicitamente planejado, portanto. OT e CA decidiram constituir CNPJ para os trabalhadores que trabalham nos galpões de criação de frangos e produção de ovos. Cada conjunto de dois, três, quatro galpões, ficaria sob a responsabilidade de um trabalhador (o "integrado"), que seria a "empresa" dos respectivos galpões.

A partir da nova forma de contrato, os trabalhadores deixaram de ter qualquer garantia legal respeitada, podendo ser dispensados a qualquer momento, sem ônus para as fazendas. Além disso, toda a remuneração passou a ser variável, de acordo com a produção obtida pelos "integrados". Desse modo, os trabalhadores são impelidos à intensificação do ritmo e prolongamento do tempo de trabalho, tanto para garantir sua sobrevivência imediata, quanto para manter seu posto de trabalho. Os próprios advogado e preposto dos empregadores admitiram isso, declarando que a "integração", por tornar os trabalhadores mais responsáveis pela produção (leia-se, mais instáveis e sem garantias), é um instrumento para tornar os trabalhadores mais dedicados e produtivos.

Portanto, a precarização do trabalho é utilizada por OT e CA como estratégia deliberada para o sucesso da reprodução do seu capital. Conforme detectava Bourdieu (1998, p. 124) ainda na década de 1990: "a precariedade se inscreve num modo de dominação de novo tipo, fundado na instituição de uma situação generalizada e permanente de insegurança, visando obrigar os trabalhadores à submissão, à aceitação da exploração". 
A organização da "integração" efetuada por OT e CA é, em linhas gerais, semelhante aos demais modelos: as aves criadas são propriedade da CA e OT do início ao final do processo; a técnica de produção é imposta pelos tomadores dos serviços, que determinam o modo de realização das atividades nos mínimos detalhes, inclusive com horários e instruções passo a passo a serem seguidas pelos trabalhadores; a remuneração percebida pelos trabalhadores é calculada por produtividade com preços definidos por OT e CA. Os trabalhadores são obrigados a trabalhar diariamente, todos os dias, e só podem descansar se alocarem, às suas expensas, outro trabalhador para substituí-los no dia de folga. Como o cuidado com os galpões demanda muito trabalho, diversos "integrados" trabalhavam em conjunto com toda a família, incluindo mulheres e filhos - diversos menores de idade, inclusive, foram detectados pelos pesquisadores in loco em efetivo labor.

A diferença entre 0 modelo mais comum de "integração" e 0 adotado por OT e CA é que no esquema desses últimos os trabalhadores sequer detêm a propriedade formal da terra. A produção toda ocorre nas propriedades de OT e CA. As casas onde moram os trabalhadores, os galpões onde laboram e os equipamentos que os constituem são propriedade de OT e CA. Os gerentes das fazendas passam as orientações, fiscalizam os serviços, fazem cobranças e dispensam os trabalhadores. Estes não têm qualquer participação no empreendimento além da sua força de trabalho, e vendem a mesma exclusivamente à OT e CA. São convocadas reuniões periódicas para cobranças relativas ao processo produtivo. Diversos trabalhadores entrevistados sequer sabiam os nomes das suas supostas empresas, cujo contador é um empregado formalmente registrado por OT e CA. Os trabalhadores são dispensados se não trabalharem de acordo com as suas imposições.

OT e CA tiveram a iniciativa de registrar CNPJ para os trabalhadores, utilizando seu contador para cuidar das formalidades e contabilidade. A terceirização efetuada pela CA e OT é uma estrita intermediação de mão de obra, pois, afinal, qual a mercadoria adquirida por OT e CA através dos "integrados"? A única possível, qual seja, a força de trabalho dos trabalhadores. Os terrenos, as aves e os ovos, a técnica de produção, a ração, a água, os equipamentos, a casa, todos os meios de produção são de CA e OT. Por óbvio, participam "integrados" com seu trabalho, exclusivamente.

$\mathrm{Na}$ intermediação de mão de obra empreendida o próprio suposto intermediador é vítima do esquema, pois submetido às mesmas condições dos demais trabalhadores em atividade nas fazendas, alguns deles formalmente registrados em nome dos "integrados", mas a maioria sem nenhuma espécie de formalização. Os trabalhadores "integrados" sequer sabiam os nomes das suas supostas empresas criadas por 0T e CA.

Um dos "integrados" entrevistados, aqui identificado por suas iniciais (ENS), informou que: 
acertou com OT que tomaria conta de dois galpões; que falou que tinha 3 filhos e que precisava trazê-los para lá e que dois eram menores; que 0T disse que não tinha problema, que eles poderiam trabalhar; que o ZL (iniciais para identificar um treposto da empresa de OT) fiscalizava 0 serviço todos os dias, que ele olhava tudo no galpão, a situação dos ovos, se galpão estava sujo ou limpo, se estava sem água para as galinhas, se tinha ração, se a produção estava boa ou ruim; que se qualquer coisa estivesse errada, ele mandava consertar; que se a produção estivesse fraca, ZL perguntava o que estava acontecendo, se a galinha estava passando fome, se estava passando sede; que após 2 anos de serviço, JR (iniciais para identificar o contador da empresa de OT') falou para ele ir a Salvador para fazer um papel que era importante para eles; que nem sabe que papéis eram esses, apenas que era para reconhecer uma firma; que ele botou o dedo nos papéis; que OT e ZL diziam que ele era empresário; que o preço dos ovos não era negociado, que a fazenda ditava o preço; que o galpão é da fazenda; que a ração é da fazenda; que a água é da fazenda; que as galinhas são da fazenda; que a casa onde ele morava é da fazenda; que ele não tinha nada como empresário, apenas o trabalho; que trabalhava todos os dias, inclusive sábados e domingos, menos quando pagava alguém para tirar sua folga; que as botas, calças e camisas fornecidas pela fazenda eram descontadas no pagamento; que ele saiu da fazenda porque ZL mandou ele tirar o adubo, e que ZL disse que se ele não tirasse o adubo, colocaria sua turma para tirar e descontaria o valor; que questionou o motivo de ZL descontar a retirada do adubo de uns e não descontar de outros; que dois dias depois ZL veio pessoalmente falar que ele estava despachado do serviço" (depoimento tomado de ENS no dia 24/03/2011).

Apesar do caráter despótico da organização do trabalho empreendida por OT e CA, o expediente de contratação e gestão do trabalho através da "integração" é 0 instrumento essencial para o exercício do controle e exploração do trabalho. Ao serem sonegadas as garantias previstas no ordenamento jurídico, os trabalhadores são obrigados a trabalhar por mais tempo e com maior intensidade. Os trabalhadores raramente descansam, laborando todos os dias ininterruptamente para garantir 0 mínimo necessário à sobrevivência e não serem dispensados.

A precarização do emprego é também corolário direto e necessário dessa forma de máscara do assalariamento, que impõe aos trabalhadores (independente de 0 "integrado" ser um intermediário ou mais um trabalhador prejudicado) as demandas do tomador de serviço sem respeito à legislação trabalhista. Como as responsabilidades da atividade são imputadas pela contratante ao "integrado", e este não tem qualquer solvência financeira, é corroborada a sonegação de todos os aspectos das normas de proteção ao trabalho. 
Como dito, OT e CA podem dispensar os trabalhadores a qualquer tempo e não são pagas rescisões contratuais. A remuneração é totalmente flexível, e mesmo assim é reduzida, sendo dividida pela família do "integrado" e ainda eventuais ajudantes (que não recebem mais do que um salário mínimo). Além disso, OT e CA não pagam 0 adicional de insalubridade devido pela natureza das atividades (conforme laudo técnico emitido pela fiscalização do trabalho), não recolhem o percentual concernente ao FGTS dos trabalhadores, não concedem férias, não pagam décimo terceiro salário. Não há pagamento das horas extras prestadas, mesmo havendo trabalho todos os dias da semana. Como dito, não há descanso, a menos que o próprio "integrado" pague um "folguista". 0 trabalho infantil era generalizado, como mecanismo adotado pelos "integrados" para evitar a corrosão da renda familiar já escassa.

Constatou-se, in loco, nos galpões de produção de ovos e criação de frangos de OT e CA, total desrespeito aos parâmetros mínimos de proteção ao trabalho. Por exemplo, no que concerne à saúde e segurança do trabalho, as instalações sanitárias estavam em péssimas condições de higiene, assim como os locais para refeição, que não tinham mesas, assentos, água para higiene pessoal, local para guarda e conservação dos alimentos. OT e CA não forneciam água potável em condições higiênicas para consumo. Eles não participavam da Comissão Interna de Prevenção de Acidentes do Trabalho Rural (CIPATR), nem eram atendidos pelo Serviço Especializado de Segurança do Trabalho Rural (SESTR). Os trabalhadores cuidavam dos frangos sem nenhuma avaliação e medida de prevenção ou proteção, manipulando fezes e cadáveres das aves. Não eram fornecidos equipamentos de proteção individual (EPI) aos trabalhadores, que laboravam com roupas pessoais, sem luvas, sem máscaras, descalços sobre as fezes das aves. Os Programas de Controle Médico (PCMSO) dos empregadores sequer reconheciam o risco biológico evidente presente nas referidas atividades (para citar um exemplo, dentre muitos possíveis, a exposição ao risco do ácaro Dermanyssus gallinae, que pode provocar lesões dermatológicas pápulo-eritematosas). A poeira formada pela mistura entre as fezes dos animais e a serragem também era risco presente no ambiente de trabalho, mas sequer considerado pelos programas, muito menos controlado. Além de não serem tomadas medidas de segurança quanto à manipulação e à eliminação de secreções, excreções e restos de animais, não eram disponibilizadas informações aos trabalhadores os referidos riscos. Não bastasse, OT e CA não submetiam os trabalhadores a qualquer exame médico.

Moradias familiares não possuíam condições sanitárias adequadas, estando em péssimas condições de higiene, não possuíam ventilação e iluminação suficientes, e estavam construídas a menos de 30 metros dos galpões de criação das aves (uma das moradias era um vestiário improvisado como casa que ficava a 6,5 metros de um galpão). As instalações sanitárias existentes não eram separadas por sexo e não tinham lavatório. 
Em suma, OT e CA conseguiram implementar um padrão de gestão que uniu as piores faces, para o trabalho, do taylorismo/fordismo e do toyotismo. Aliou o despotismo do capital no controle da força de trabalho com a insegurança típica da flexibilização do trabalho, adicionando uma pitada de retórica para envolvimento dos "integrados" que seria cômica, não fosse trágica: "Que após 2 anos de serviço, JR falou para ele ir a Salvador para fazer um papel que era importante para eles; que nem sabe que papéis eram esses, apenas que era para reconhecer uma firma; que ele botou o dedo nos papéis; que seu OT e ZL diziam que ele era empresário" ("integrado" ENS em 24/03/2011).

\section{REFERÊNCIAS}

ANTUNES, Ricardo. Adeus ao trabalho? Ensaio sobre as metamorfoses e a centralidade do mundo do trabalho. São Paulo: Cortez Editor, 2008.

BOURDIEU, Pierre. Contrafogos: táticas para enfrentar a invasão neoliberal. Rio de Janeiro, Jorge Zahar, 1998.

CONCEIÇÃO, Edney. Territorialidade da avicultura de corte na Babia: o sistema integrado de produção avícola nos municípios de São Gonçalo dos Campos e Conceição da Feira - BA. UFBA - Salvador - Bahia, 2007.

MINISTÉRIO PÚBLICO DO TRABALHO. Ação civil pública, 2007. Disponível em: $<$ actbr.org.br/uploads/.../188_MPTPRxsouzacruz_fumicultores.pdf> Acesso em: 01 maio, 2011.

MARX, Karl. O capital: crítica da economia política. Rio de Janeiro, Civilização Brasileira, 2002.

PINCELLI, Ângela Cristina. Trabalho infanto-iuvenil na fumicultura $e$ responsabilidade social empresarial: o discurso da Souza Cruz. Dissertação de Mestrado, Programa de Pós-Graduação em Sociologia Política, Universidade Federal de Santa Catarina, Florianópolis, 2005.

PELEGRINI, Djalma Ferreira; CLEPS JUNIOR, João. 0 programa de integração da Rezende/Sadia no triângulo mineiro/alto Paranaíba no contexto das transformações na suinocultura brasileira. V Congresso de Ciências Humanas, Letras e Artes. Ouro Preto, agosto de 2001. Disponível em: <www.ichs.ufop.br/conifes/anais/../ogt1601.htm>. Acesso em: 01 maio, 2011.

SCARE, Roberto Fava; SILVA, Vinícius Mazza; TAVARES, Letícia Serra. Planejamento e implantação do pólo de avicultura integrada de Barreiras-BA. In: NEVES, Marcos Fava; Castro, Luciano Thomé (Orgs). Agricultura integrada: inserindo pequenos produtores de maneira sustentável em modernas cadeias produtivas. Ribeirão Preto, Editora Atlas, 2010. 